\title{
Neural progenitor cells from postmortem adult human retina
}

\author{
E J Mayer, D A Carter, Y Ren, E H Hughes, C M Rice, C A Halfpenny, N J Scolding, A D Dick
}

Br J Ophthalmol 2005;89:102-106. doi: 10.1136/bjo.2004.057687

See end of article for authors' affiliations

.....................

Correspondence to: Andrew D Dick,

Department of Clinical Sciences, University of Bristol, Bristol Eye Hospital, Lower Maudlin Street, Bristol BS1 2LX, UK; a.dick@bristol.ac.uk

Accepted for publication 10 September 2004

\begin{abstract}
Background: Given the presence of neural progenitor cells (NPC) in the retina of other species capable of differentiating into multiple neural components, the authors report the presence of NPC in the adult human retina. A resident population of NPC suggests that the retina may constitutively replace neurons, photoreceptors, and glia.

Methods: Adult human postmortem retinal explants and cell suspensions were used to generate cells in tissue culture that display the features of NPC. The phenotype of cells and differentiation into neurons was determined by immunocytochemistry. Dividing cells were labelled with 5-bromo-2-deoxyuridine (BrdU) and neurospheres were generated and passaged.

Results: Cells labelled with nestin, neurofilament M (NFM), rhodopsin, or glial fibrillary acidic protein (GFAP) grew out from explant cultures. BrdU labelling of these cells occurred only with basic fibroblast growth factor (FGF-2). Dissociated retina and pars plana generated primary neurospheres. From primary neurospheres, NPC were passaged to generate secondary neurospheres, neurons, photoreceptors, and glia. BrdU labelling identified dividing cells from neurospheres that differentiated to express NFM and rhodopsin.

Conclusion: The adult human retina contains NPC and may have the potential to replace neurons and photoreceptors. This has implications for the pathogenesis and treatment of retinal disorders and degenerations, including glaucoma, and those disorders associated with retinal scarring.
\end{abstract}

S tem cells have the capacity to self renew, proliferate, and have no limitation to their potential differentiation. Progenitor cells can divide but have restricted differentiation potential. ${ }^{1}$ In the adult vertebrate central nervous system (CNS), neural progenitor cells (NPC) have been identified and shown to generate neurons and glia. ${ }^{2-6}$ Developing and postnatal vertebrate animal retina contains NPC, which divide, generate neurospheres, and undergo neuronal and glial differentiation. ${ }^{7-10}$ In humans CNS derived NPC have been successfully cultured from the adult brain ${ }^{11-14}$ but not the adult retina. Neural progenitor cells have been isolated from the human retina while it is still immature and undergoing development. ${ }^{15-17}$ It has previously been shown that cells from developing retinal pigment epithelial (RPE) could generate other types of cells ${ }^{18}$ and adult human derived RPE cell lines are capable of generating neuronal cells. ${ }^{19}$

Nestin is an intermediate filament that serves a marker of neural progenitor cells. ${ }^{20}$ The adult human retina contains nestin $^{+}$neuronal and glial cells, as does epiretinal scar tissue. ${ }^{21}$ This evidence suggests that NPC ${ }^{22}$ may exist throughout life in the human retina and be misdirected in retinal scarring disorders including proliferative vitreo-retinopathy, diabetes, retinal detachment, and ocular inflammatory disorders. ${ }^{21}$

\section{MATERIALS AND METHODS \\ Cell preparation and culture}

Donor tissue from the National Eye Bank (Bristol Eye Hospital) was used with research consent and ethical approval (Central and South Bristol Research and Ethics project number E5866). Eyes were obtained from donors without known concomitant ocular disease. A class II microflow biological safety cabinet was used for tissue culture experiments. Retinal explants and cell suspensions were cultured in DMEM:HAMS F12 (Gibco, UK) on the membrane of a cell culture insert. Culture medium was supplemented with fibroblast growth factor (FGF-2, Sigma, UK) $20 \mathrm{ng} \mathrm{ml}^{-1}$, epidermal growth factor (EGF, Sigma, UK) $20 \mathrm{ng} \mathrm{ml}^{-1}$, and/or $10 \%$ fetal calf serum (FCS, Sigma, UK). Explants were incubated for $4-5$ days at $35^{\circ} \mathrm{C}$ with $5 \% \mathrm{CO}_{2}$ then fixed and stained. Cell suspensions were prepared from whole neural retina and pars plana using enzymatic digestion at $35^{\circ} \mathrm{C}$ (with trypsin, DNAse, and collagenase) and mechanical disruption (trituration). Vital cell counts were based on trypan blue exclusion on a haemocytometer. Cells suspensions were cultured for 2-3 weeks in medium supplemented with $20 \mathrm{ng} /$ $\mathrm{ml} \mathrm{FGF}$ alone to generate neurospheres. Neurospheres were subsequently plated on upturned fibronectin coated slides and cultured for $1-2$ weeks. Dividing cells were labelled in culture medium supplemented with $10 \mu \mathrm{M}$ BrdU (5-bromo2-deoxyuridine, BD Biosciences, Europe) as per the manufacturer's instructions. Experiments were performed in triplicate (or more) runs to ensure reproducibility, on 2048 hour postmortem normal adult human retina and pars plana. We have used 34 donor eyes for explants cultures and more than 40 donor eyes have been used to generate primary cell suspensions, which all have generated neurospheres. The donor age range was $15-87$ years (mean age of 56).

\section{Immunocytochemistry}

Fixed specimens (30 minutes in 1\% filtered paraformaldehyde) were washed, permeabilised, and blocked $(0.02 \%$ Triton X-100 and 5\% serum for 30 minutes) then incubated with primary antibodies overnight at $4^{\circ} \mathrm{C}$. BrdU labelled specimens underwent DNA denaturation (using $2 \mathrm{~N} \mathrm{HCl}$ for 30 minutes at $35^{\circ} \mathrm{C}$ ) after fixation.

The following primary antibodies were used: mouse anti-human nestin (1:200 Chemicon, CA, USA); mouse anti-human vimentin (1:200 Chemicon, CA, USA) and rabbit anti-human neurofilament M (1:200 Chemicon, CA, USA),
Abbreviations: BrdU, 5-bromo-2-deoxyuridine; CNS, central nervous system; EGF, epidermal growth factor; FCS, fetal calf serum; FGF, fibroblast growth factor; GFAP, glial fibrillary acidic protein; NFM, neurofilament M; NPC, neural progenitor cells; RPE, retinal pigment epithelium 


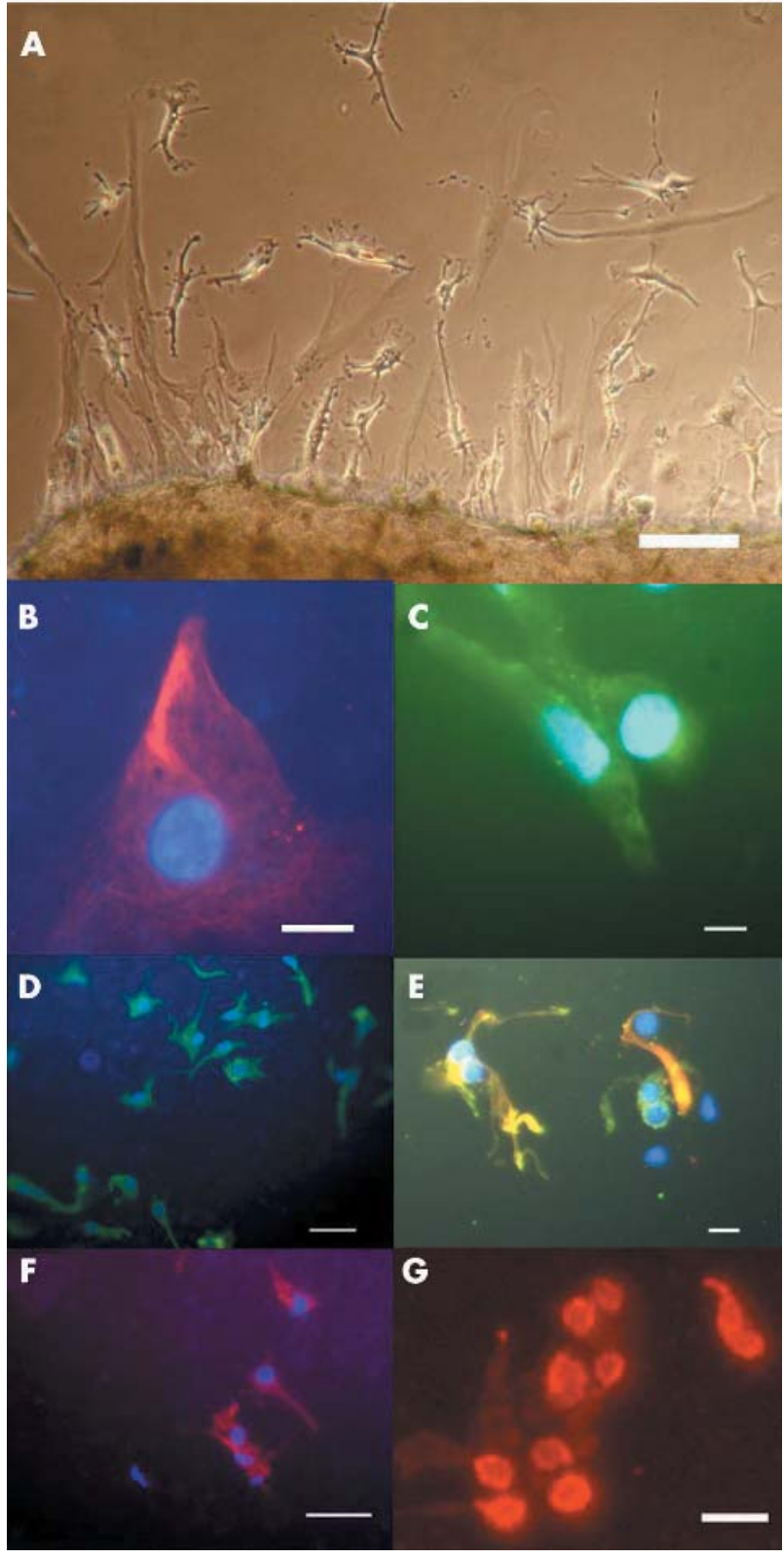

Figure 1 Cells derived from explant cultures of normal postmortem adult human retina. A phase contrast view of a retinal explant with cells migrating out at 5 days (A). These cells expressed nestin in red (B) and vimentin (C). Cells also expressed green GFAP (D), indicating a glial lineage and some were labelled with GFAP in green and nestin in red (E). Some cells expressed red NFM (F) indicating a neuronal lineage. Other cells were labelled with rhodopsin (G), indicating a rod photoreceptor lineage. Nuclei are counterstained with DAPI (blue). Bars: $100 \mu \mathrm{m}(\mathrm{A}) ; 10 \mu \mathrm{m}(\mathrm{B}, \mathrm{C}) ; 50 \mu \mathrm{m}(\mathrm{D}) ; 10 \mu \mathrm{m}(\mathrm{E}) ; 50 \mu \mathrm{m}$ (F), $10 \mu \mathrm{m}$ (G).

rabbit anti-human rhodopsin (1:200, Santa Cruz Biotechnology Inc, USA), mouse anti-human BrdU (Biosource International, Europe), and rabbit anti-human GFAP (1:200 Sigma, UK), CD90 (1:50, Santa Cruz Biotechnology Inc, USA) with their respective sera. Secondary antibody incubations (1:250) for 1 hour at room temperature used FITC antimouse or anti-rabbit conjugate (Sigma, UK), anti-rabbit TRITC conjugate (Sigma, UK), and/or anti-mouse Cy3 (Chemicon, CA, USA) conjugate. In some studies nuclei were counterstained with DAPI (4, 6-diamidino-2 phenylindole). Cells were counted on a fluorescence microscope (Leitz Dialux 22EB at $\times 40$ magnification), and photographed

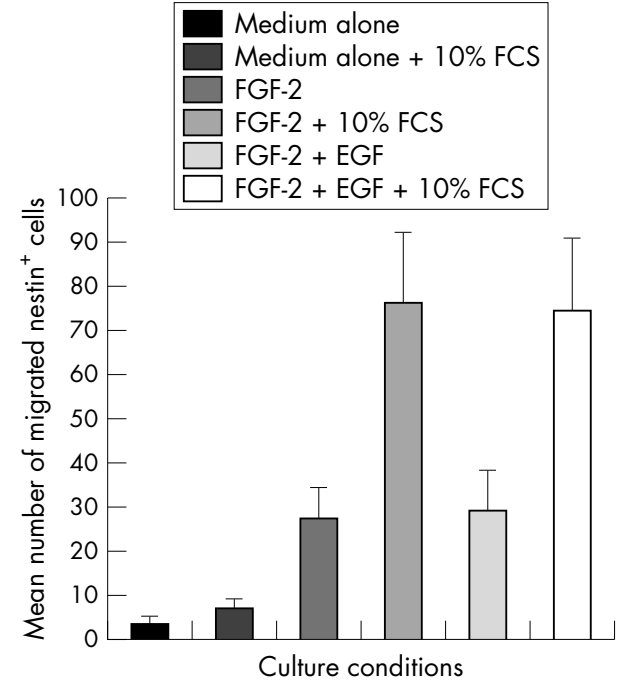

Figure 2 Growth factor supplements increase nestin+ cell outgrowth from retinal explants from different retinal regions. Media supplements FGF-2 (fibroblast growth factor) and FCS (fetal calf serum) (10\%) increased the outgrowth of nestin ${ }^{+}$cells from whole retina explants. The presence of EGF (epidermal growth factor) did not increase nestin ${ }^{+}$cell outgrowth (see text and table 1). Data are shown as mean of three experiments and the average of three retinal regions, which are differentiated in table 1 (error bars show SD).

(Nikon E990 digital camera, analysed using Adobe Photoshop). Data analysis was performed using factorial analysis of variance.

\section{RESULTS}

\section{Explant cultures}

Cultured explants of adult human retina seeded cells expressing nestin, vimentin, rhodopsin, NFM, and GFAP into the surrounding area (fig 1). Supplementation of the culture medium with trophic substances increased the number of nestin ${ }^{+}$cells surrounding explants as shown in figure $2 \mathrm{~A}$ and table 1 . Explants were taken as $5 \mathrm{~mm}$ punch biopsies from different retinal regions: peripheral or post-oral retina being the most anterior; equatorial or mid-peripheral retina was used as an intermediate region; posterior or central retina was taken from within $10 \mathrm{~mm}$ of the optic disc. Explants from all regions were subjected to different growth factor combinations and the migration of nestin ${ }^{+}$cells from the explants was studied. Main effects were identified for FGF-2, FCS and the origin of retinal explants and they interacted with each other. The retinal region from which retinal explants were taken had an effect on the number of nestin ${ }^{+}$cells growing out: post-oral (anterior) and equatorial sites did not differ, but seeded approximately three times more cells than posterior explants $(F=13.19, p<0.001)$. The addition of FCS to the culture medium increased the number of nestin ${ }^{+}$cells growing out overall approximately twofold $(\mathrm{F}=22.57, \mathrm{p}<0.001)$ and FGF-2 increased numbers overall approximately threefold $(\mathrm{F}=54.36, \mathrm{p}<0.001)$. EGF had no additional effect either alone with FGF-2, in interaction with FCS, or with the site of explant origin $(\mathrm{F}=2.6 \mathrm{l}, \mathrm{NS})$. Following $\log$ transformation of the data, all three main effects were retained and remained highly significant, but all interactions were abolished and no longer significant. This means that the effects of the three factors FGF-2, FCS and site of explant origin were independent of each other and multiplicative-that is, if the effects of FGF-2, FCS, and the site of explant origin were to change numbers threefold, twofold, and threefold separately and independently, then the effect of a combined treatment is to simply multiply the 
Table $1 \mathrm{Nestin}^{+}$cell migration from retinal explants

\begin{tabular}{llll}
\hline & \multicolumn{3}{l}{ Number of nestin $^{+}$cells migrated from retinal regions } \\
\cline { 2 - 4 } Culture conditions & Posterior & Mid-peripheral & Anterior \\
\hline Medium alone & $0(0)$ & $1(1.7)$ & $7(11)$ \\
Medium alone + 10\% FCS & $6(6.4)$ & $5(3.8)$ & $10(1.5)$ \\
FGF & $11(10.8)$ & $30(27.5)$ & $41(19.5)$ \\
FGF + 10\% FCS & $21(14.8)$ & $100(33.2)$ & $106(27.5)$ \\
FGF + EGF & $13(17.6)$ & $40(29.7)$ & $34(29.5)$ \\
FGF + EGF + 10\% FCS & $18(19.1)$ & $100(49.3)$ & $105(22.9)$ \\
\hline
\end{tabular}

Data are tabulated to show the effect of different growth factors on nestin ${ }^{+}$cell migration from retinal explants of different retinal regions. Values presented are means calculated from different experimental runs. Standard deviation (SD) values are cited.

factors for the separate treatments that apply. Again EGF was without any additional effect.

The more anterior the retina, the more nestin ${ }^{+}$cells grew out from retinal explants. The regional differences in the number of nestin ${ }^{+}$cells migrating from retinal explants reflect the number of nestin ${ }^{+}$cells found in these regions (table 1 and Mayer et $a l^{21}$ ) with more cells found in retinal regions closer to the ora serrata. There was more limited outgrowth of nestin ${ }^{+}$cells from retinal explants taken from the posterior pole. Minimal attempts to culture explants of pars plana were made as it is not possible to reliably separate the pigmented and non-pigmented epithelial layers. There is also a difficulty in ensuring that underlying choroidal cells (which are on the other side of Bruch's membrane) do not contaminate the culture experiments if cells from the pars plana are used. It has previously been shown that this anatomically distinct and separate region contains cells that are able to generate neurons. ${ }^{23}$ Secondly, different culture conditions produced large variations in the number of nestin ${ }^{+}$ cells. The greatest outgrowth of nestin ${ }^{+}$cells occurred with FGF-2 giving a threefold increase and FCS giving a twofold increase, while EGF had no further effect. There was a statistically significant effect of retinal region on the

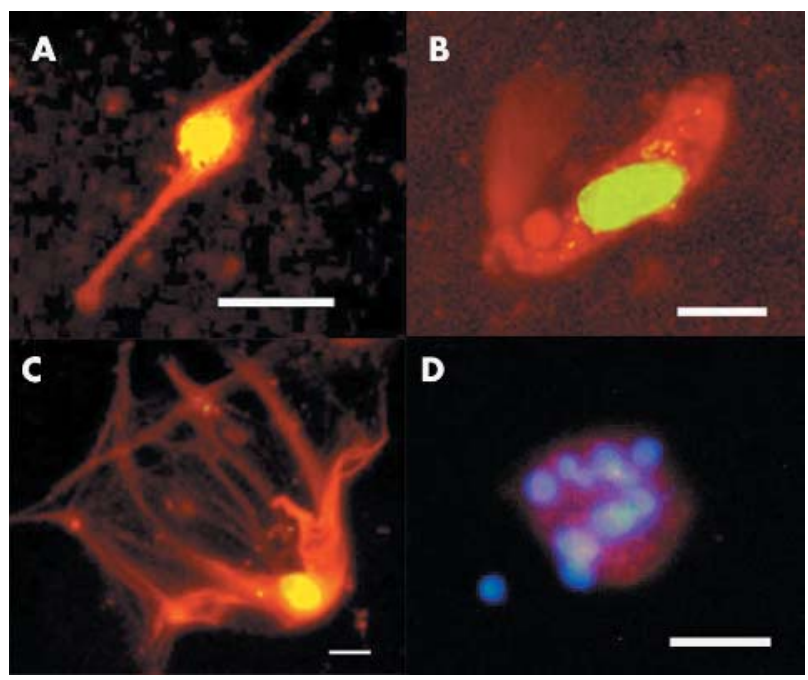

Figure 3 Cells derived from dividing (BrdU labelled) precursors. $\mathrm{BrdU}^{+}$nestin ${ }^{+}$neural progenitor cells migrated from adult human retinal explants divide (A) then differentiate into neurons $(B)$ as shown by double labelled $\mathrm{BrdU}^{+}$(green) and $\mathrm{NFM}^{+}$(red) cells. Dissociated primary neurospheres were exposed to BrdU for 1 week. Labelled cells (green nucleus) differentiated to express NFM (red) (C) when plated onto fibronectin coated coverslips. Early passaged neurospheres in which all nuclei identified with blue DAPI are also labelled with green BrdU (seen as cyan) and nearly all cells stain with red rhodopsin (D) when plated onto collagen coated coverslips. Bars: A-C, $10 \mu \mathrm{m} ; \mathrm{D}, 25 \mu \mathrm{m}$. outgrowth of nestin ${ }^{+}$cells from the retinal explants $\left(F_{2,17}\right.$ $=5.79, \mathrm{p}=0.02$ ).

Within the different retinal regions a similar profile of response to the growth factors was observed, although the actual numbers were reduced when retinal explants were from retina posterior to the equator. Addition of FGF-2 and FCS increased the outgrowth of nestin ${ }^{+}$cells from cultured adult human retinal explants. In this system EGF seemed to confer little additional effect.

To establish whether the cells identified were derived from precursors that had undergone division, BrdU labelling was studied. Overall, $46.5 \%$ (plus or minus 22.3 for the mean of three experiments) of nestin ${ }^{+}$cells migrating from explants were also $\mathrm{BrdU}^{+}$in the presence of FGF-2 and FCS (fig 3A). $\mathrm{Nestin}^{+}$and $\mathrm{NFM}^{+}$cells that were BrdU ${ }^{+}$migrated out from cultured explants only in the presence of FGF-2 and FCS (fig 3B). In explant cultures of adult human postmortem retina, FGF-2 was required to induce the division and/or migration of dividing cells that expressed nestin and/or NFM, as in its absence none was observed.

\section{Generation of neurospheres}

Following tissue dissociation of retina or pars plana to a single cell suspension and subsequent culture in FGF-2 supplemented media for up to 1 month neurospheres were generated (fig 4A). Although pars plana epithelium was used to generate neurospheres only limited experiments were carried out for the reasons cited above. In the presence of FGF-2 alone, on average one neurosphere was generated for every $200-300 \times 10^{4}$ live retinal cells in suspension. Neurospheres have been generated at all attempts and begin to form at between 4-5 days in culture (fig 4B). Initially small neurospheres are seen to form either from the division or the adhesion of cells. These may or may not attach to substratum. Small neurospheres contain nestin ${ }^{+}$cells and $\mathrm{NFM}^{+}$cells (fig 4C). Extrapolating cell diameter to neurosphere diameter, after 3 weeks neurospheres were estimated to contain $3 \times 10^{6}$ cells. After 3 weeks fibronectin coated upturned coverslips induced neurospheres to seed cells into the surrounding area and/or attach and develop processes (fig 4D). If the neurospheres attach to the substratum they may or may not send out processes. The processes from the neurospheres are $\mathrm{NFM}^{+}$or nestin ${ }^{+}$, arising from cells within the sphere (fig 4E), and sometimes accompanied by GFAP ${ }^{+}$ cells (fig 4F). The cell processes were also labelled with CD90 indicating that they either arose from neurons of a retinal ganglion cell phenotype or are bone marrow mesenchyme derived $^{24}$ (fig 4G). Larger neurospheres contained nestin ${ }^{+}$ cells and cells that were positive for NFM, CD90, or GFAP (fig $4 \mathrm{H}, \mathrm{I}, \mathrm{J}$ ). As with retinal explants, formed neurospheres seeded cells onto the surrounding culture area only in the presence of FGF-2. Secondary (passaged) neurospheres were derived from dissociated primary neurospheres. 


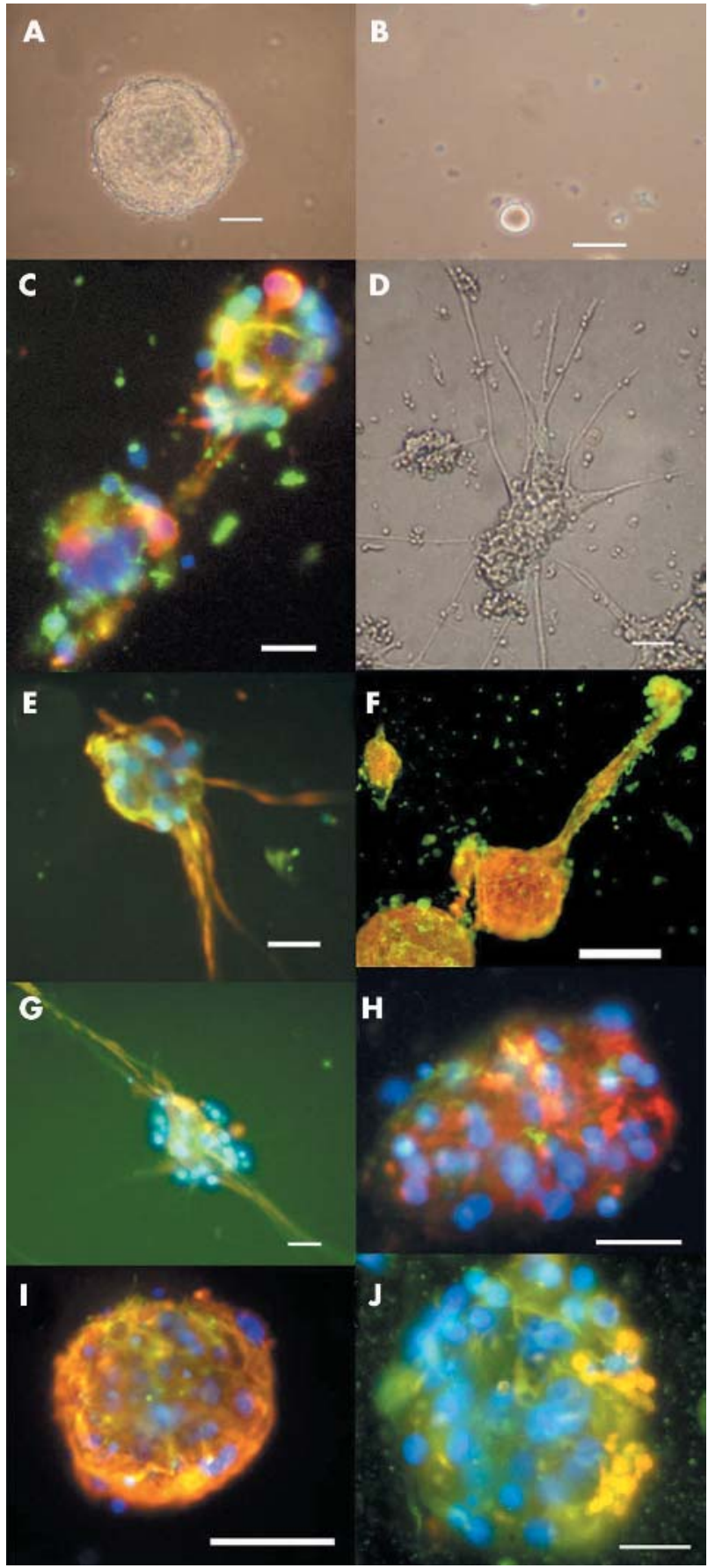

Figure 4 Neurospheres derived from adult human retinal NPC. Free floating neurospheres at 3 weeks seen in phase contrast (A) develop from an earlier smaller neurosphere (B). Small neurospheres contain red nestin ${ }^{+}$and green NFM ${ }^{+}$cells (C). Neurospheres may attach to fibronectin coated coverslips and seed cells, which attach or remain unattached to the surrounding area (D). The latter may or may not develop processes. Neurosphere processes contain red nestin ${ }^{+}$and green NFM $(E)$ and may be accompanied by green $\mathrm{GFAP}^{+}$cells $(\mathrm{F})$. The processes are also positive for green $\mathrm{CD} 90(\mathrm{G})$ indicating a retinal ganglion or mesenchymal marrow cell lineage. Larger neurospheres contained red nestin and green NFM (H), red nestin and green GFAP (I). In a later neurosphere there were red nestin and green CD90 labelled cells (J). Nuclei were counterstained with DAPI (blue). Bar: $25 \mu \mathrm{m}(\mathrm{A}-\mathrm{H}$, J); $50 \mu \mathrm{m}(\mathrm{I})$.

Dissociation of 2 week old neurospheres to a single cell suspension gave between 250 and 280 live cells per neurosphere. The resultant cell suspension was cultured in medium with FGF-2 and N2 supplement (Gibco, UK). Most cells subsequently attached to the substratum and differentiated. Secondary neurospheres formed at a rate of one for every three primary neurospheres. Neurospheres exposed to BrdU, when resuspended and plated onto fibronectin coated coverslips, generated $\mathrm{BrdU}^{+} \mathrm{NFM}^{+}$cells, in the presence of FGF-2 (fig 3C). We found a subset of small passaged neurospheres, which contained predominantly rhodopsin ${ }^{+}$cells, showed BrdU labelling of all nuclei that were identified with DAPI (fig 3D). Cells that differentiated to express NFM or rhodopsin under these conditions were derived from dividing cells in neurospheres, cultured from the adult human retina. In this culture system FCS was not required to observe BrdU labelling of cells.

\section{DISCUSSION}

Having identified nestin ${ }^{+}$neurons, photoreceptors, and glia in the adult human retina and in retinal scar tissue ${ }^{21}$ potentially derived from NPC, we looked for NPC in the adult human retina. The data presented here demonstrate a population of NPC (cells that can under appropriate conditions divide, produce neurospheres, and differentiate into neurons, photoreceptors, and glia) within the adult human retina. These cells proliferate in and migrate from cultured retinal explants when appropriately stimulated. The presence of $\mathrm{BrdU}^{+}$cells, which are also $\mathrm{NFM}^{+}$or rhodopsin ${ }^{+}$demonstrates that cells of a neuronal phenotype are probably derived from dividing NPC in these culture systems. BrdU labels dividing cells and may also label cells undergoing DNA repair. ${ }^{25}$ We have attempted to overcome this by generating neurospheres and passaging them. Furthermore, the finding that in early passaged neurospheres, all cells are $\mathrm{BrdU}^{+}$and all seem to be of the same phenotype (fig 3D) provides further evidence that these cells maybe derived from dividing cells generating clones. The generation of neurospheres and their passage provides further evidence of NPC behaviour in these cells obtained from primary cultures of adult human postmortem retina. The features of these cells are in keeping with the behaviour and characteristics of embryonic and adult CNS derived NPCs. ${ }^{22}$ The adult human retina has cells within it that may be able to replace neurons and photoreceptors under the right conditions. Previous attempts to identify cells in the adult human eye have centred on the choroid and sclera. ${ }^{23}$ The sclera and choroid are anatomically separated from the retina by a barrier that does not allow cellular passage. Unlike the retina, these regions are not part of the CNS and such cells would only gain access to the retina in cases of extreme trauma, questioning the physiological importance of NPC in these regions.

The gradient of NPC density as detected by nestin ${ }^{+}$cell migration from explants of different retinal regions in culture falls off in the posterior retinal regions. This is very similar to the gradient observed for nestin ${ }^{+}$cells in different retinal regions that we previously reported..$^{21}$ Certainly some radial cells, which are anatomically similar to Muller cells, are nestin $^{+}$in the adult human retina and more numerous in the anterior retina. ${ }^{21}$ Some radial retinal cells have progenitor cell properties and occur in a gradient compatible with that observed in the present study. ${ }^{26}$ Our future experiments will be aimed at a better characterisation of the cells within the adult human retina that display the properties of NPC.

The presence of NPC has obvious implications for ongoing cellular replacement, repair, regeneration and cellular responses to disease in the retina. Whether or not these cells undergo such a process in vivo has yet to be demonstrated. The presence of nestin ${ }^{+}$neurons and glia in the adult human retina $^{21}$ and the ability of the retina to show late recovery in massive degenerative disease, ${ }^{27}$ implies that cell populations may undergo replacement in the adult human retina. For 
example, some types of glaucoma (loss of retinal ganglion cells) may represent a neurodegenerative disease similar to Alzheimer's disease. ${ }^{21}{ }^{28}$ Furthermore, the presence of nestin ${ }^{+}$ cells in specimens of retinal scar tissue ${ }^{21}$ in a number of diseases causing retinal scarring including diabetic retinopathy, proliferative vitreoretinopathy, idiopathic preretinal scarring, macular holes, and ocular inflammatory disease implies that these cells may be misdirected by signals present in retinal disease, to form scar tissue. ${ }^{21}$

The behaviour of NPC derived from other CNS sites varies according to the anatomical source of the cells, ${ }^{29}$ the age of the donor (greater yields from younger tissue), ${ }^{12}{ }^{29}$ differences in culture conditions, duration, number, and mode of passage. ${ }^{30}$ Such findings would be expected from the sequentially restricted fashion in which NPC develop, ${ }^{31}$ as reflected by the observations of site specific integration of transplanted human fetal neural progenitor cells in rodent brain $^{32} 33$ and their response to injury. ${ }^{34}$ Before considering the transplantation of NPC into the retina we must understand their behaviour in health and try to control them in disease. Differences in the latter conditions may offer therapeutic targets.

In summary, these data demonstrate the presence of FGF-2 responsive adult human retinal NPC that divide, express nestin, produce neurospheres, and differentiate to express markers of neuronal, photoreceptor, or glial lineage. This is the first report of NPC from adult human postmortem retina or pars plana. The possibility of intrinsic potential for cellular replacement would explain the presence of nestin ${ }^{+}$cells, neurons, and glia in the adult human retina, ${ }^{21}$ and late retinal recovery in massive degenerative disease. ${ }^{27}$ This may require that we re-interpret our understanding of retinal disorders, including neurodegenerative conditions, like some types of glaucoma (loss of retinal ganglion cells). As the only part of the CNS directly visible in vivo, by non-invasive means, the retina may offer a unique and accessible opportunity to study the role of NPC in neurodegenerative and CNS diseases in humans.

\section{ACKNOWLEDGEMENTS}

We gratefully acknowledge the help and advice of Professor SB Dunnett with statistical analysis.

We acknowledge the following for support, the National Eye Research Centre, the Guide Dogs for the Blind Association, the Iris Fund for the Prevention of Blindness, and the McAlpine Trust.

Tissue was provided by the CTC National Eye Bank at Bristol Eye Hospital.

\section{Authors' affiliations}

E J Mayer*, D A Carter*, Y Ren, E H Hughes, A D Dick, Department of Clinical Sciences, University of Bristol, Bristol Eye Hospital, Lower Maudlin Street, Bristol BS1 2LX, UK

C M Rice, C A Halfpenny, N J Scolding, Institute of Clinical

Neurosciences, University of Bristol, Department of Neurology, Frenchay Hospital, Bristol BS16 1LE, UK

*These authors contributed equally to this work.

Competing interests: The authors declare no competing financial interests.

\section{REFERENCES}

1 Potten CS, Loeffler M. Stem cells: attributes, cycles, spirals, pitfalls and uncertainties. Lessons for and from the crypt. Development 1990;110:1001-20.
2 Gage F. Mammalian neural stem cells. Science 2000;287:1433-8.

3 McKay R. Stem cells in the central nervous system. Science 1997;276:66-71.

4 Graziadei PP, Monti-Graziadei GA. Neurogenesis and plasticity of the olfactory sensory neurons. Ann N Y Acad Sci 1985;457:127-42.

5 Alvarez-Buylla A, Theelen M, Nottebohm F. Proliferation "hot spots" in adult avian ventricular zone reveal radial cell division. Neuron 1990;5:101-9.

6 Weiss S, Dunne C, Hewson J, et al. Multipotent CNS stem cells are present in the adult mammalian spinal cord and ventricular neuroaxis. J Neurosci 1996; 16:7599-609

7 Ahmad I, Dooley CM, Thoreson WB, et al. In vitro analysis of a mammalian retinal progenitor that gives rise to neurons and glia. Brain Res 1999;831:1-10.

8 Tropepe V, Coles BL, Chiasson BJ, et al. Retinal stem cells in the adult mammalian eye. Science 2000;287:2032-6.

9 Fischer AJ, Reh TA. Identification of a proliferating marginal zone of retinal progenitors in postnatal chickens. Dev Biol 2000;220:197-210.

10 Ahmad I, Tang L, Pham H. Identification of neural progenitors in the adult mammalian eye. Biochem Biophys Res Commun 2000;270:517-21.

11 Roy NS, Wang S, Jiang L, et al. In vitro neurogenesis by progenitor cells isolated from the adult human hippocampus. Nat Med 2000;6:271-7.

12 Palmer TD, Schwartz PH, Taupin P, et al. Progenitor cells from human brain after death. Nature 2001;411:42-3.

13 Nunes MC, Roy NS, Keyoung HM, et al. Identification and isolation of multipotential neural progenitor cells from the subcortical white matter of the adult human brain. Nat Med 2003;9:439-47.

14 Johansson CB, Svensson M, Wallstedt L, et al. Neural stem cells in the adult human brain. Exp Cell Res 1999;253:733-6.

15 Kelley MW, Turner JK, Reh TA. Regulation of proliferation and photoreceptor differentiation in human fetal retinal cell cultures. Invest Ophthalmol Vis Sci 1995;36:1280-9.

16 Yang $P$, Seiler MJ, Aramant RB, et al. In vitro isolation and expansion of human retinal progenitor cells. Exp Neurol 2002;177:326-31.

17 Klassen H, Ziaeian B, Kirov II, et al. Isolation of retinal progenitor cells from post-mortem human tissue and comparison with autologous brain progenitors. J Neurosci Res 2004:77:334-43.

18 Zhao S, Thornquist SC, Barnstable CJ. In vitro transdifferentiation of embryonic rat retinal pigment epithelium to neural retina. Brain Res 1995:677:300-10.

19 Amemiya K, Haruta M, Takahashi M, et al. Adult human retinal pigment epithelial cells capable of differentiating into neurones. Biochem Biophys Res Com 2004;316:1-5.

20 Dahlstrand J, Lardelli M, Lendahl U. Nestin mRNA expression correlates with central nervous system progenitor cell state in many but not all regions of the developing central nervous system. Dev Brain Res 1995;84:109-29.

21 Mayer EJ, Hughes EH, Carter DA, et al. Nestin positive cells in the adult human retina and in epiretinal membranes. $\mathrm{Br} J$ Ophthalmol 2003;87:1154-8.

22 Rao M. Multipotent and restricted precursors in the central nervous system. Anatomical Record 1999;257:137-48.

23 Arsenijevic Y, Taverney N, Kostic C, et al. Non-neural regions of the adult human eye: a potential source of neurons? Invest Ophthalmol Vis Sci 2003;44:799-807.

24 Vogel W, Grunebach F, Messam CA, et al. Heterogeneity among human bone marrow derived mesenchymal stem cells and neural progenitor cells. Haematologica 2003;88:126-33.

25 Cooper-Kuhn CM, Kuhn HG. Is it all DNA repair? Methodological considerations for detecting neurogenesis in the adult brain. Dev Brain Res 2002;134:13-21.

26 Fischer AJ, Reh TA. Potential of Muller glia to become neurogenic retinal progenitor cells. Glia 2003;43:70-6.

27 Nakamura M, Yamamoto M. Variable pattern of visual recovery of Leber's hereditary optic neuropathy. Br J Ophthalmol 2000;84:534-5.

28 Gu H, Wang S, Messam CA, et al. Distribution of nestin immunoreactivity in the normal adult human forebrain. Brain Res 2002;943:174-80.

29 Ostenfeld T, Joly E, Tai YT, et al. Regional specification of rodent and human neurospheres. Brain Res Dev Brain Res 2002;134:43-55.

30 Akagi T, Haruta M, Akita J, et al. Different characteristics of rat retinal progenitor cells from different culture periods. Neurosci Lett 2003;341:213-16.

31 Cepko $\mathrm{CL}$, Austin $\mathrm{CP}$, Yang $\mathrm{X}$, et al. Cell fate determination in the vertebrate retina. Proc Natl Acad Sci USA 1996;93:589-95.

32 Fricker RA, Carpenter MK, Winkler C, et al. Site-specific migration and neuronal differentiation of human neural progenitor cells after transplantation in the adult rat brain. J Neurosci 1999;19:5990-6005.

33 Englund U, Biorklund A, Wictorin K. Migration patterns and phenotypic differentiation of long-term expanded human neural progenitor cells after transplantation into the adult rat brain. Dev Brain Res 2002;134:123-41.

34 Kelly S, Bliss TM, Shah AK, et al. Transplanted human fetal neural stem cells survive, migrate, and differentiate in ischaemic rat cerebral cortex. Proc Natl Acad Sci 2004;101:11839-44. 